\title{
Yuntai Fuzzy PID Control and Simulation
}

\author{
Min Ji 1, a \\ 1Xijing University, \\ Shaanxi Xi'an ,China \\ aE-mail: 995010771@qq.com \\ Xiaoping Yang 3, c \\ 3Shaanxi step industrial co., LTD, \\ Shaanxi Xi'an ,China \\ cE-mail: 41564103@qq.com
}

\begin{abstract}
This article first introduces the basic theory of fuzzy control and design of the general steps of the fuzzy controller, the basic principle of fuzzy PID is presented. Then use particle swarm algorithm to optimize fuzzy rules. In the end, the optimized fuzzy PID triaxial stability for unmanned aerial vehicle haeundae simulation experiment, and make comparison with the classic PID control algorithm. The simulation results show that the PSO parameters optimization of fuzzy PID system has a better effect, optimization of the fuzzy PID control algorithm in unmanned aerial vehicle three axis stabilized yuntai control achieves a good control effec.
\end{abstract}

Keywords-fuzzy control; fuzzy rules; PID control; simulate

\section{INTRODUCTION}

Fuzzy control system is a system based on knowledge and rule, and it is a core part of the "if-then" rule knowledge base. Fuzzy control algorithm is the basis of a kind of intelligent control algorithm based on fuzzy set theory, fuzzy language variable and fuzzy logic reasoning. It was based on the fuzzy set, fuzzy relation, fuzzy inference to simulate human thinking and to perform logic judgment, synthesis reasoning, handle and solve routine methods is difficult to effectively solve the problem. Learned the fuzzy control algorithm has the characteristics of fuzziness in the human mind. Broadly speaking, the fuzzy control algorithm is the application of the fuzzy set theory as a whole system of a kind of control method. Part of the fuzzy control system mainly includes the fuzzy processing, fuzzy reasoning, fuzzy, so we choose the combination of different methods, different fuzzy control system can be constructed..

\section{YUNTAI FUZZY PID CONTROLLER DESIGN}

In the process of simulation, we select yuntai frame as a simulation model of Fig .1. as well as model.

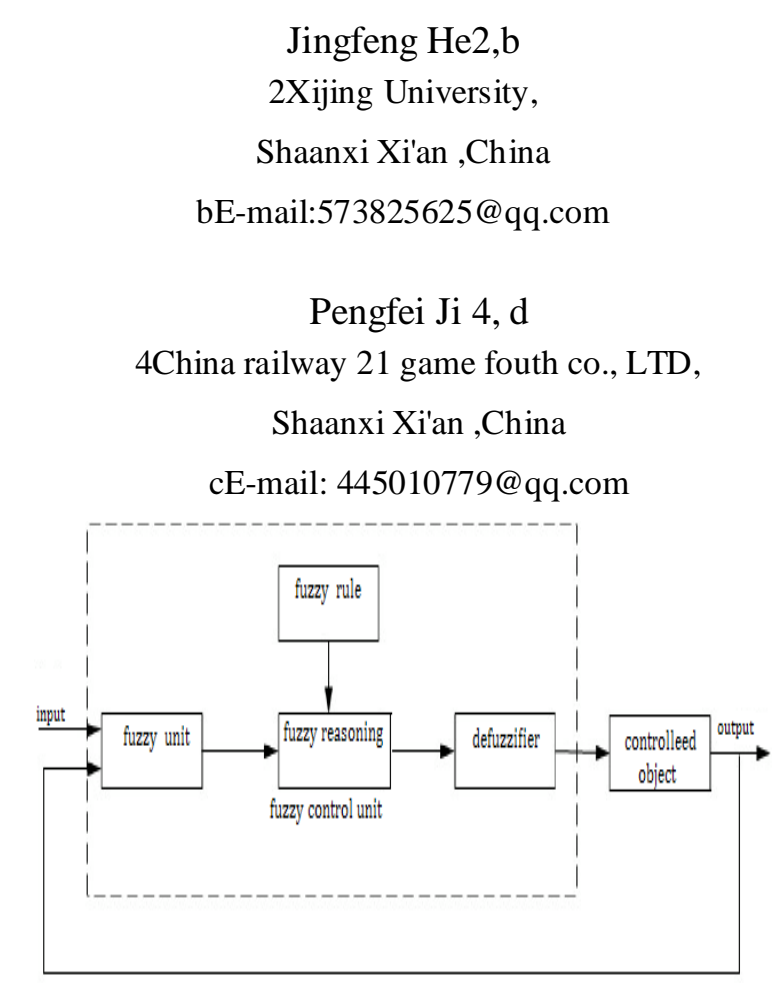

Figure 1. Fuzzy control system block diagram

\section{A. the language variable}

The camera optical axis Angle deviation E:

Fuzzy comprehensive domain: [3, 3]

Fuzzy subsets: [NB, NM, NS, ZE, PS, PM, PB]

Membership functions take triangular membership functions, as shown in Fig .2:

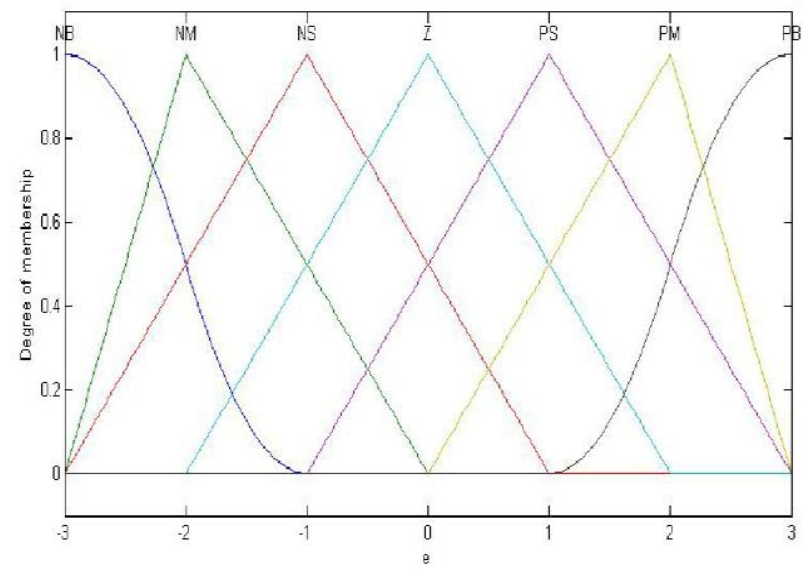

Figure 2. error E membership functions

Deviation rate EC:

Fuzzy comprehensive domain: [3, 3]

Fuzzy subsets: [NB, NM, NS, ZE, PS, PM, PB]

Membership functions take triangular membership functions, as shown in Fig .3: 


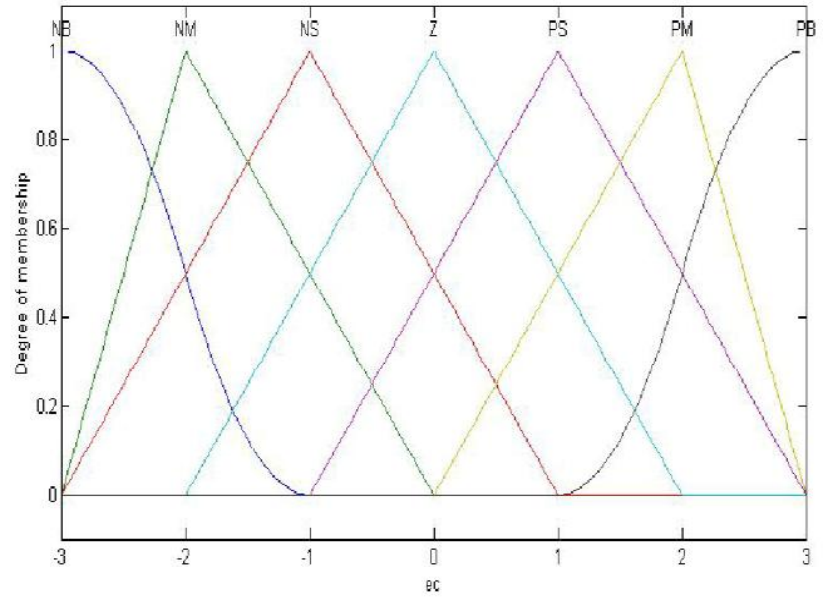

Figure. 3 error rate of the EC membership functions

B. the output language variables

Proportional coefficient increment $\Delta \mathrm{Kp}$ :

Fuzzy comprehensive domain: [to 30, 30]

Fuzzy subsets: [NB, NM, NS, ZE, PS, PM, PB]

Membership functions take triangular membership functions, as shown in Fig .4:

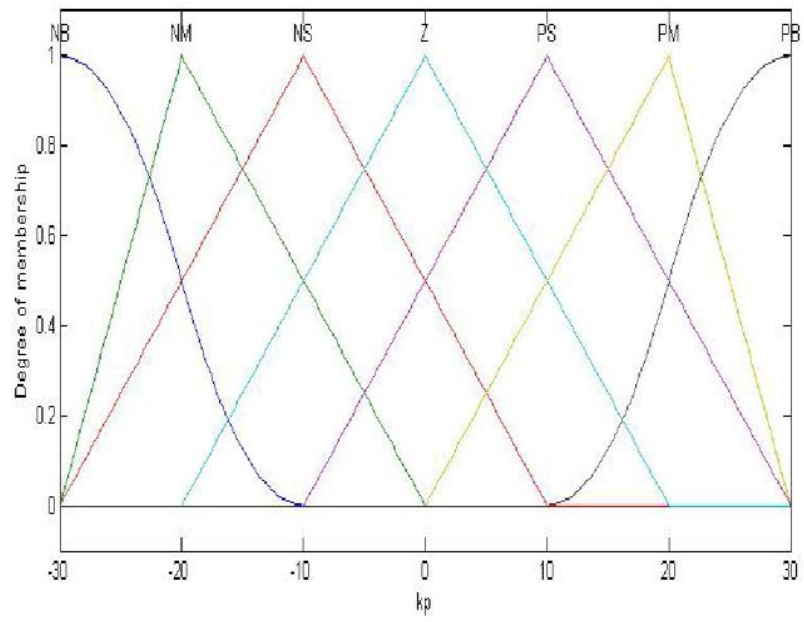

Figure 4. $\Delta \mathrm{Kp}$ 's membership functions

Integral coefficient increment $\Delta \mathrm{Ki}$ :

Fuzzy comprehensive domain: [to 6, 6]

Fuzzy subsets: [NB, NM, NS, ZE, PS, PM, PB]

Membership functions take triangular membership functions, as shown in Fig .5.

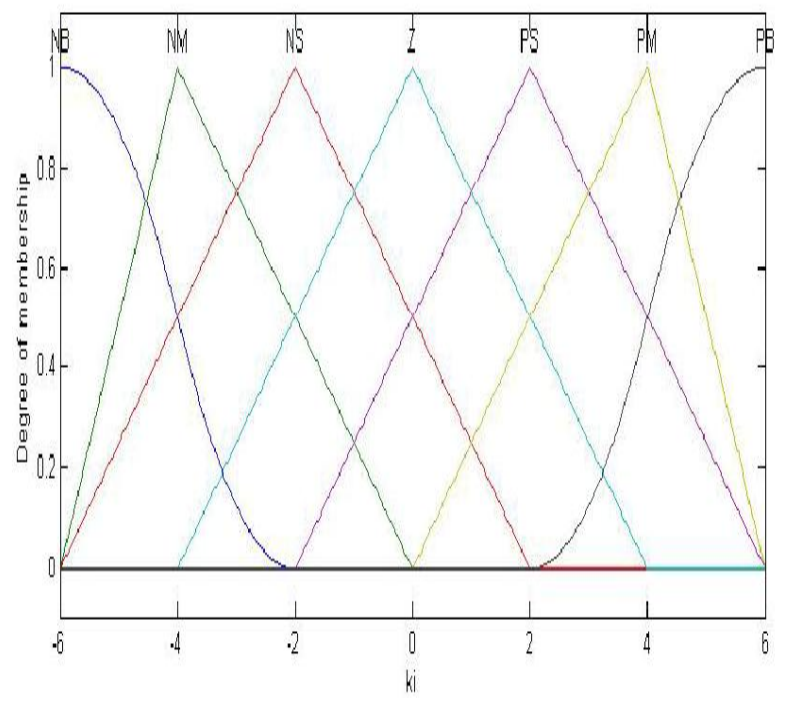

Figure 5. $\Delta \mathrm{Ki}$ membership functions

Differential coefficient increment $\Delta \mathrm{Kd}$ :

Fuzzy comprehensive domain: $[3,3]$

Fuzzy subsets: [NB, NM, NS, ZE, PS, PM, PB]

Membership functions take triangular membership functions, as shown in Fig . 6:

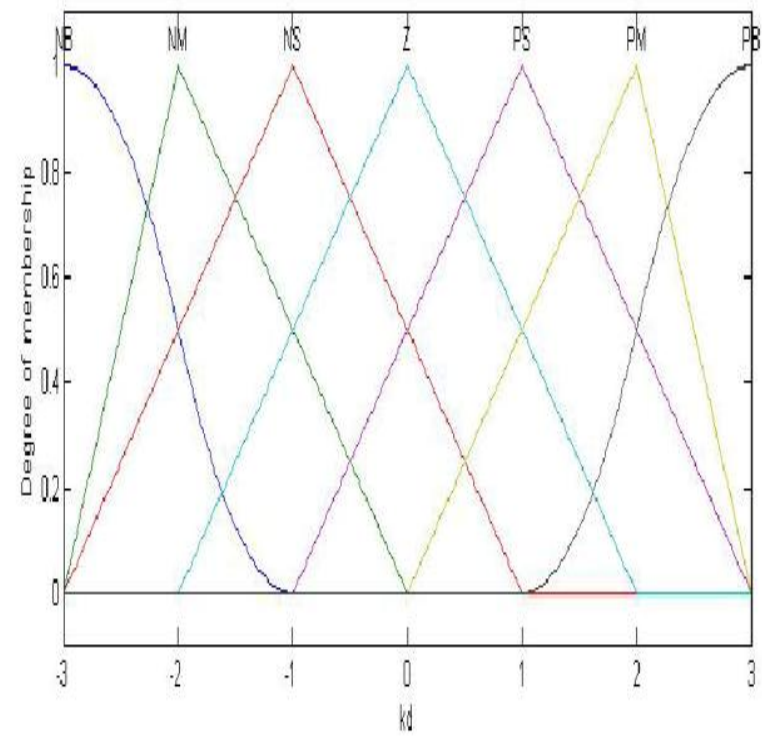

Figure 6. $\Delta \mathrm{Kd}$ membership functions

\section{C. the fuzzy control rule tabl}

Design of the core part is the summary of technical staff technical knowledge and practical experience, set up suitable fuzzy control table. The following table 1 to table 3 is a kind of for $\Delta \mathrm{Kp}, \Delta \mathrm{Ki}, \Delta \mathrm{Kd}$ three parameters setting of the fuzzy control table, respectively. 
Table $1 \Delta$ Kp fuzzy rule table

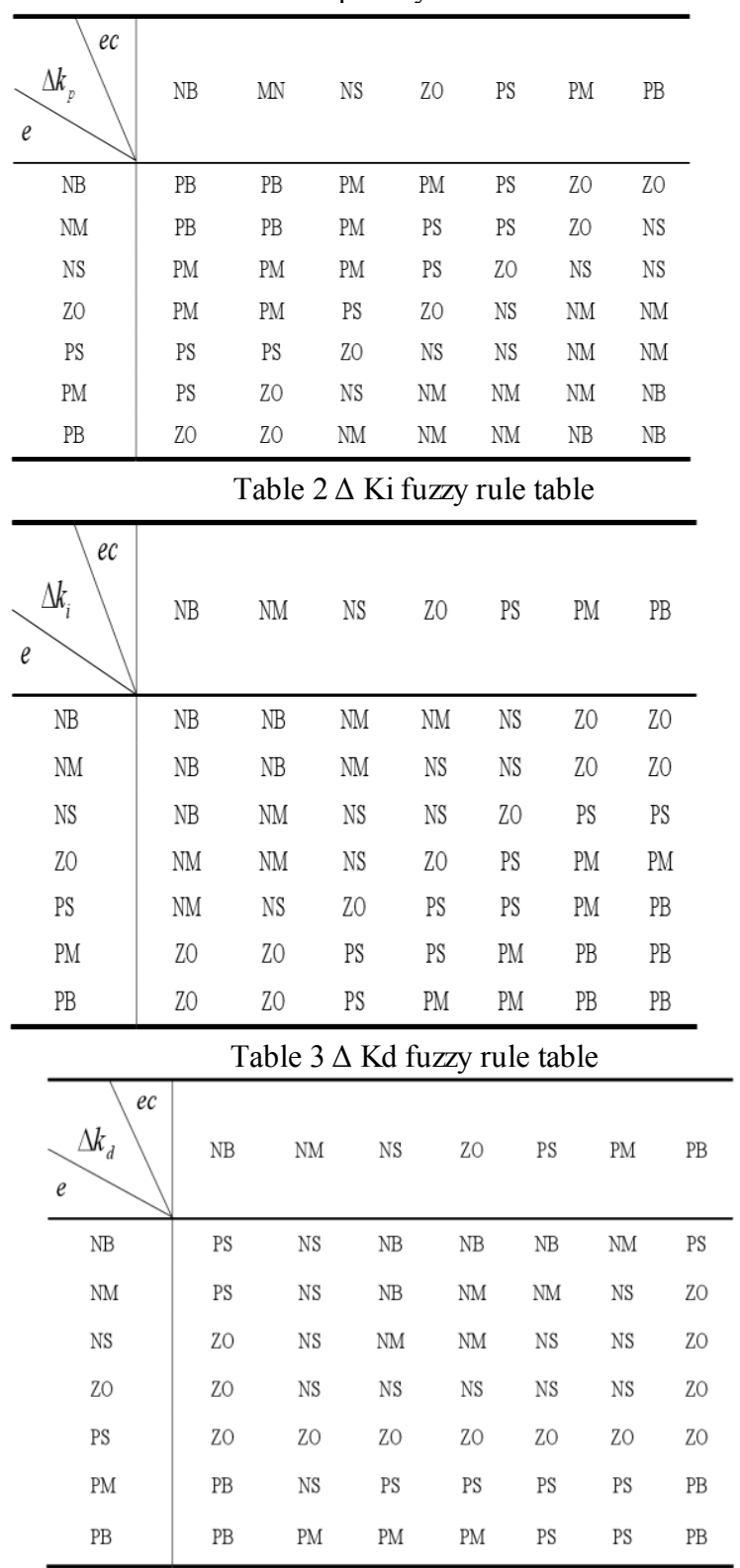

Fuzzy control rule table about $\Delta \mathrm{Kp}, \Delta \mathrm{Ki}, \Delta \mathrm{Kd}$ sets up, and uses the following method for adaptive adjustment.

Article 49 rules of each rule sets with product of reasoning machine, single value center of fuzzy and average solution by combining fuzzy device, namely gets parameters $\Delta \mathrm{Kp}, \Delta \mathrm{Ki}, \Delta \mathrm{Kdonline}$ adjustment formula:

$$
\begin{aligned}
& \Delta k_{p}= \frac{\sum_{l=1}^{49} \bar{y}_{p}^{l} \mu_{A^{l}}(e(t)) \mu_{\mathbf{B}^{l}}(e c(t))}{\sum_{l=1}^{49} \mu_{A^{l}}(e(t)) \mu_{\mathbf{B}^{l}}(e c(t))} \\
& \Delta k_{d}= \frac{\sum_{l=1}^{49} \bar{y}_{d}^{l} \mu_{A^{l}}(e(t)) \mu_{\mathbf{B}^{l}}(e c(t))}{\sum_{l=1}^{49} \mu_{A^{l}}(e(t)) \mu_{\mathbf{B}^{l}}(e c(t))} \\
& \Delta k_{i}=\frac{\sum_{l=1}^{49} \bar{y}_{i}^{l} \mu_{A^{l}}(e(t)) \mu_{\mathbf{B}^{l}}(e c(t))}{\sum_{l=1}^{49} \mu_{A^{l}}(e(t)) \mu_{\mathbf{B}^{l}}(e c(t))}
\end{aligned}
$$

Plug in the following equation to calculate the current $\mathrm{K}_{\mathrm{p}}, \mathrm{K}_{\mathrm{i}}, \mathrm{K}_{\mathrm{d}}$

$$
\left\{\begin{array}{l}
k_{p}=k_{p 0}+\Delta k_{p} \\
k_{i}=k_{i 0}+\Delta k_{i} \\
k_{d}=k_{d 0}+\Delta k_{d}
\end{array}\right.
$$

\section{FUZZY PID SIMULATION RESULTS ANALYSIS}

The simulation tool of Matlab is R2010a, fuzzy PID controller using $\mathrm{M}$ functional. The initial fuzzy PID controller parameter $\mathrm{K}$ p0 $=19, \mathrm{~K}$ i0 $=0.02, \mathrm{Kd} 0=0$.Signal is the unit step signal, sampling time is $1 \mathrm{~ms}$.

In order to validate the advantages of the fuzzy PID controller, we put the classic PID and fuzzy PID simulation comparison. The simulation results are shown in Fig .7. 


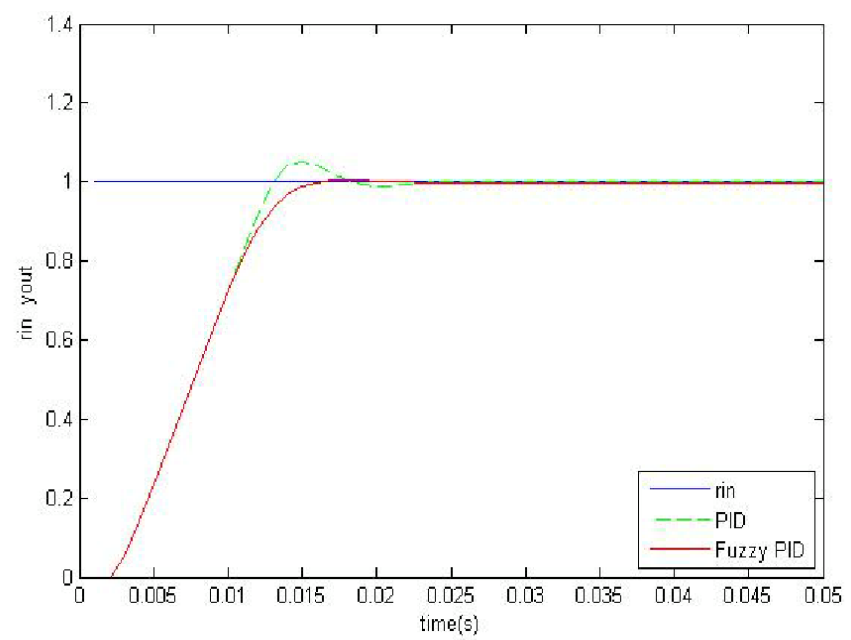

Figure 7. unit step signal without noise fuzzy PID simulation results

We can see from the simulation curve of fuzzy PID regulating time faster, $0.02 \mathrm{~s}$, and the whole process of regulation without overshoot; Classic PID is $0.025 \mathrm{~s}$, there is stable after a steady-state error.

When joining the white noise amplitude is 0.1 , the simulation results shown in Fig.8.

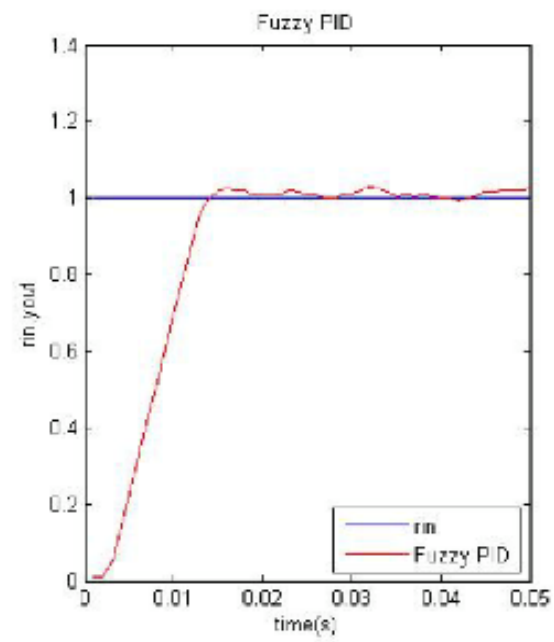

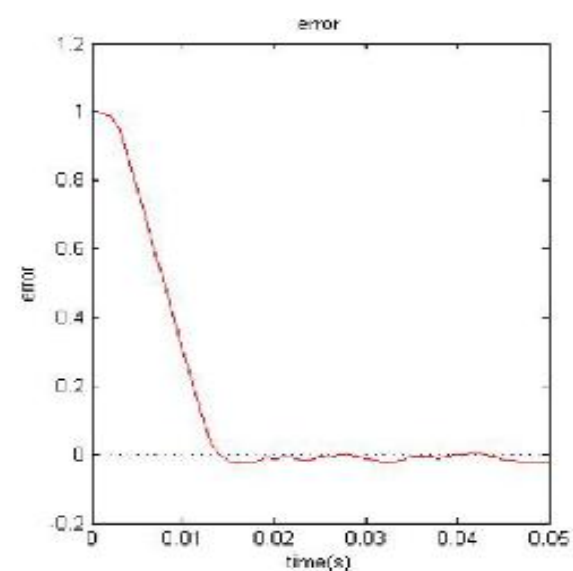

Figure 8. magnitude 0.1 white noise is fuzzy PID simulation results

\section{CONCLUSIONS}

The simulation results show that the fuzzy PID although can quickly achieve a stable state, but a largesteady-state error, it must add filter technology in control algorithm, to suppress the interference of noise exist in the system, the system has high precision.

\section{REFERENCES}

[1] MEHRA R K. On the identification of variances and adaptive Kalman filtering[J]. IEEE Trans.Automatic Control,1970,

[2] AC5(2):175-174

[3] Stuartr Bennett. The past of PID controller[J].Annual Reviews in Control,2001,25:43-53.

[4] Valerie Paul, Benot Ricard, Andre Zaccarin. Step-stare technique for airborne high-resolution in frared imaging[J].SPIE-The international Society for Optical Engineering,2004,04:128-138

[5] Slobodan N. Vukosavic. Suppression of Torsional Oscillations in A High-Performance Speed Servo Drive[J].IEEE Trans. on Industry Electronics. 1998,45(1):108-117

[6] Marcelo C A, Douglas E E. Novel Kalman Filtering Method for the Suppression of Gyroscope Noise Effects in Pointing and Tracking Sys tems[J].Optical engineering.1995,34(10):3016-3030

[7] SNJayaramamurthyameshJain.AnAPProachtotheSegInentationofTe xturedDynamicSeenes[J].ComPuterGraPhiesandImageProcessing , 1983,1:239 - 26

[8] Eberhart R C, Shi Y H. Particle swarm optimization: developments, applications andresources[C]//Proceedings of the IEEE congress on Evolutionary Computation. Seoul, Korea:IEEE, 2001:81-86

[9] G. Eason, B. Noble, and I. N. Sneddon, "On certain integrals of Lipschitz-Hankel type involving products of Bessel functions," Phil. Trans. Roy. Soc. London, vol. A247, pp. 529-551, April 1955.

[10] J. Clerk Maxwell, A Treatise on Electricity and Magnetism, 3rd ed., vol. 2. Oxford: Clarendon, 1892, pp.68-73.

[11] I. S. Jacobs and C. P. Bean, "Fine particles, thin films and exchange anisotropy," in Magnetism, vol. III, G. T. Rado and H. Suhl, Eds. New York: Academic, 1963, pp. 271-350.

[12] J.A.R. Krishna Moorty, Rajeev Marathe, V.R. Sule'. HœControl Law for Line-of-sightStabilization for Mobile Land Vehicles[J]. Optical Engineering. 2002,41(11):2935-2944 